\title{
Paths to acceptance
}

\author{
The advancement of scientific knowledge is an uphill struggle against 'accepted wisdom'
}

$\mathrm{T}$ he super-detective Sherlock Holmes, invented by British author Sir Arthur Conan Doyle (1859-1930), famously held that, "when you have eliminated the impossible, whatever remains, however improbable, must be the truth." One might assume that this purely logical principle applies equally well to new scientific ideas, given that scientists, like Holmes, seek to uncover the truth. Ideally, a new hypothesis that helps to explain previously unexplainable observations should therefore replace previous theories. Unfortunately, scientists do not always follow a path of pure logic, as the German physicist Max Planck (1858-1947) once observed, "[a] new scientific truth does not triumph by convincing its opponents and making them see the light, but rather because its opponents eventually die, and a new generation grows up that is familiar with it."

The history of science is replete with theories that only became accepted by the scientific community after a long and protracted uphill battle. However, not every scientist has faced the amount of hostility and ridicule that Charles Darwin (1809-1882) did when he proposed his grand theory of evolution in 1859. In explaining how life on Earth evolved, and implying that humans were not formed in the image of the creator, but rather were descended from apes, Darwin invoked the ire of the scientific community and the church. Similarly, in the 1920s, Nils Bohr (1895-1962) and Werner Heisenberg (1901-1976) proposed a new theory to explain observations at the atomic and sub-atomic level that defied Newtonian mechanics. However, it took many years for quantum mechanics to be widely accepted, not least because Albert Einstein (18791955), the leading physicist at the time, invoked a higher authority to dismiss it: "I, at any rate, am convinced that He [God] does not throw dice." Stanley Prusiner met a similar fate when he proposed that proteins could be infectious agents; his prion theory, which won him the Nobel Prize in Physiology or Medicine in 1997, needed many years before it was accepted.
It is not only the hypotheses that shatter well-established knowledge and theories that are ridiculed, dismissed or rejected. Even a simple insight-for example, that the bacterium Helicobacter pylori, rather than physiological problems, causes stomach ulcers-is not always quickly accepted. Australian physician Barry Marshall won some of the most prestigious scientific prizes, including the Robert Koch and the Lasker Prizes, before the clinical community grudgingly accepted that he was right. For his insight, Marshall was eventually awarded the Nobel Prize together with Robin Warren in 2005.

$\mathrm{N}$ ot surprisingly, there are still many scientists who struggle to find acceptance for their ideas. Among them is Marcus Pembrey, a clinical geneticist at the Institute of Child Health in the UK and a former consultant to the British Government on genetic testing policy. Pembrey proposed that the behaviour and environment of parents can shape the biological future health of their children and grandchildren-an idea that contradicts classical theories on inheritance. In the mid-1980s, Pembrey was head of clinical genetics at the Great Ormond Street Hospital/Institute of Child Health in London, UK, where he studied fragile X syndrome - an inherited form of mental retardation with an unusual pattern of inheritance. Pembrey, who was making his reputation as a successful speculator-albeit outside his field-proposed that the disease advances progressively from a 'pre-mutation' stage to full manifestation over the course of three generations.

His proposal raised eyebrows among the scientific community. "Fortunately, the idea was testable and the molecular nature of the pre-mutation and its progression was worked out by others seven years later," Pembrey noted. "The discovery of other 'dynamic mutations' causing different diseases followed and the principles are now part of mainstream medical genetics." Yet, this first insight led him to view unexplained patterns of inheritance as research opportunities.
He took another bite of the apple and quickly found another paradox: when a bit of chromosome 15 from either parent is deleted, it can lead to either Angelman syndrome-a type of mental retardation-or Prader-Willi syndrome-a condition marked by an insatiable appetite. It turns out that when the damaged chromosome is inherited from the father, Prader-Willi results, whereas if the deletion is on the chromosome from the mother, then Angelman occurs. This early evidence of genomic imprinting led Pembrey to suggest that during meiosis and gametogenesis-when egg and sperm are formed - the trans-generational flow of information, affected by external factors such as nutrition, might be "moulded by Darwinian evolution into a mechanism for transgenerational adaptation - an idea that was then, and to some scientists is still, utter heresy," he said. In 1994, he gave a wrap-up talk at a meeting on DNA imprinting in Florence, Italy, during which he first proposed this idea as "light-hearted speculation."

\section{The history of science is replete with such theories that only became accepted by the scientific community after a long and protracted uphill battle}

To support his speculation, Pembrey used epidemiological data from the socalled Dutch Hunger Winter in 1944-1945, which showed that well-fed women whose mothers had starved during mid-pregnancy were producing smaller babies than women whose mothers had not starved at that point. However, the effects could only be explained by means other than non-Mendelian transmission of information, for example through epigenetic inheritance.

Next, Pembrey sought data on the male line. "There was no relevant data in the literature. And the Neo-Darwinists argued that any environmental influences on gene activity (i.e. epigenetic programming) beyond those actually causing DNA mutations would be 

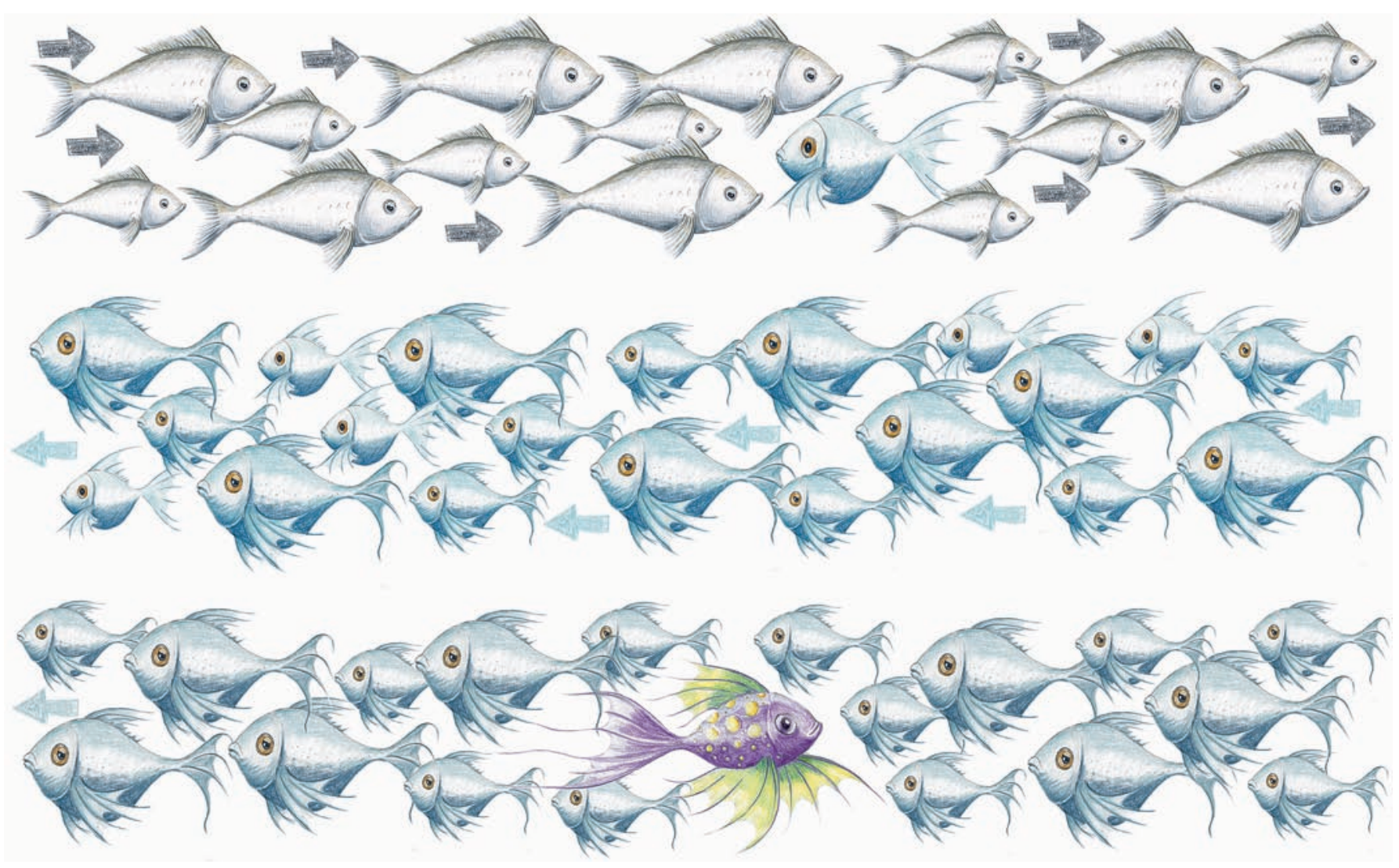

wiped clean between generations," he said. In 2000, Lars-Olov Bygren, a retired Swedish public health doctor, wrote an e-mail to Pembrey saying that he had observed that the availability of food to the paternal grandfather affected the longevity of the grandchild. This led to their collaboration and progression of the theory.

$\mathrm{O}$ ver time, the idea that epigenetic factors-which influence the expression and control of genes - can be passed on to offspring gained acceptance, and even clinical and public health relevance (Hunter, this issue). Pembrey said: "We see that the environment and behaviour of parents can change the biological inheritance of their children and grandchildren, thus turning the nature [versus] nurture debate on its head."

However, getting to this point was not easy and it might have helped that Pembrey was an outsider: he is convinced that if he had been a molecular geneticist, rather than a clinical geneticist, his ideas on the transmission of environmental exposure between generations would have been stillborn. If he had had a career in the fields about which he was speculating, he might not have put forward his ideas; "I wasn't encumbered," he said. "I just wondered what the explanations are for the things that I saw. Initially I looked around for papers and mined them for data."

Yet, Pembrey still experienced how conventional thinking can get in the way of new ideas. He recalled asking a top statistician to review a paper by Bygren on transgenerational longevity effects, "I asked him about the statistics. He said statistics were fine [but] the idea is implausible. That's what you run into, and not just from the statisticians." However, Pembrey also acknowledged that the scientific community gives him a bit more leeway for his excursions into epigenetics, perhaps because his first hunches on fragile $X$ were verified at that time.

$\mathrm{P}$ embrey crosses disciplinary lines; so does Susan Lindquist, a geneticist and biochemist at the Massachusetts Institute of Technology (MIT; Cambridge, MA USA), whose work on protein folding involves various areas including medicine, biology and nanoscience. Similar to Pembrey, Lindquist is challenging the common wisdom-namely that DNA is the only carrier of heritable information-because her work implies that proteins, more specifically prions, also carry information across generations.

\section{...there are still many scientists who struggle to find acceptance for their ideas}

Such excursions into other fields can beand often are-viewed as intrusive. "If you've been studying in a field all your life, having someone from outside from a completely different field come and tell you something important could be rather irritating. It's just human nature," Lindquist commented. Part of the problem is a turf issue, she said, but also a gap in understanding because experts in other fields "don't get why my ideas work."

Lindquist's research group came up with a model for diseases of the nervous system by using yeast. "People just refuse to believe that could be valid. It just doesn't make any sense to them," she noted. "But it's a protein folding problem and [...] protein trafficking problem and that's pretty much common 
to all forms of life, so you really can model some of these things in a very simple system and get someplace really fast."

Lindquist's laboratory has also used yeast to show that acquired traits can be passed on through prion proteins without any change in the DNA or RNA. Her group showed that heat-shock proteins, a group of molecular chaperones, can reveal hidden variation in fruit flies and cress plants under certain environmental conditions. Some of the variations might be harmful, whereas others might spur on the pace of evolution and produce new traits.

\section{Such excursions into other fields can be-and often are-viewed as intrusive}

The response to her publications has been rather mixed. "Some people are very open. They really love it. They find new ideas very exciting. It gives them a kind of Aha! kind of insight," Lindquist said. "Then there's a whole other group of people who are hostile to us. It's sort of polarizing. Basically you see some people saying, 'Oh, that's phenomenal,' and others saying, 'No, I don't believe it.' It's just a difficult situation to be in." In fact, Lindquist's experience seems to prove Planck's dictum of the acceptance of new ideas: "I have less problem with the younger people actually than I do with the more established people in the field because I think the younger people have had more understanding of more recent biochemistry," she said.

L indquist, who was named one of America's top 50 women scientists in 2002, also faced another obstacle when she tried to promote her theories: it is hard for a woman to present a new idea in traditionally male-dominated scientific precincts. "Even when people don't have any overt prejudice, it's just harder for them to have some woman tell them they've got a brand-new, fabulous idea that's a great insight that they didn't have before. And I think that contributes to some extent to this as well," she said.

Over time, Lindquist learned how to deal with this reluctance: "I try not to be too reactive when people are reactionary. I try to calm myself down; it's hurtful at times." In addition, her experience has shown that a one-to-one conversation often helps to convince other people. "It's really a burden to do a lot of traveling and go to meetings [...] but I'm finding I need to do that because usually when I explain it directly to the people I'm talking to, they get it, but it takes quite a bit of explanation and people don't want to take the time to read papers. When you publish in great places like Nature and Science, for example, you have to cut down your paper to such an extent. You can't put all the extra words in it you'd like to put in," she said.

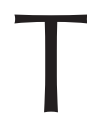
om Tuschl-a chemist and head of the Laboratory for RNA Molecular Biology at Rockefeller University in New York, NY, USA-by contrast, cannot complain about a lack of interest in his work: his insights have rapidly spread within the research community. Tuschl is one of the leading proponents of a true revolution in mammalian genetics: namely that RNA is not just a passive carrier of information within the cell, but that it plays a much more active role in the control of gene expression. His is studying the regulatory functions of RNA, including RNA interference (RNAi) and microRNA - the latter of which he discovered-and RNA-guided modifications to chromatin, and is now looking for links between RNAi and genetic disorders such as fragile X syndrome.

Tuschl thinks his approach has caught on rapidly - maybe too rapidly_as thousands of laboratories around the world are now using RNAi-based techniques to study gene expression. Part of the reason for this quick acceptance, he commented, is a commercial market for these tools and the publishor-perish pressures on academics. "It's a very exciting field. And if you look into Nature and Science every third week or so, there's a paper on it," he said.

However, this uncritical uptake of RNAi and microRNA tools has created problems of its own. Each time a new regulator of tumour growth is discovered, say, in colon cancer, then, "everybody who works on lung cancer will immediately rush there to figure out if it's also in lung cancer," Tuschl commented. "Then they look at what technology has been applied and they immediately apply the existing technology onto their collection of material." In addition, commercial and clinical interests facilitate and promote this research, which might also explain its quick acceptance as a research tool. "As a consequence, there are a lot of advertisements of new microRNA products to measure gene expression to RNAi gene silencing reaction products in the same issue of high-profile journals that regularly publish RNAi-related manuscripts," Tuschl noted.

As a result, Tuschl thinks that many dubious papers are published that just claim a disease association based on the use of RNAi tools. "The crazier the idea, the more interested they [journals] are in accepting it," he said. "What the papers are missing is [the] simple pathological evidence that what they are studying is indeed expressed in the tumour tissue, for instance." He said a lot of this literature "disappears" over time because it is not replicated and eventually lacks an understanding of the underlying science.

s the saying goes, nothing is more
powerful than an idea whose time
has come. Yet, many proponents of new ideas have a 'hard time' up until their colleagues become convinced of the merits. It is not only the reluctance of established research fields and communities that slow down the uptake of revolutionary hypotheses, but also a general reluctance to explore new ideas and support those who do so. As Pembrey commented, many more speculative ideas need to be considered, but scientific journals usually do not have the space for such conceptual papers. In addition, the main research funding organizations do not make 'big bets' to support speculative research. "Funding bodies like the UK Medical Research Council encourage scientists to think out of the box," Pembrey said. "But in the end these [applications] turn into minor projects."

\section{It is not only the reluctance of established research fields and communities that slow down the uptake of revolutionary hypotheses, but also a general reluctance to explore new ideas and support those who do so}

Despite the difficulties, there is some comfort for those who think that they have a revolutionary insight that remains largely ignored: history has nearly always proven that, in the end, truth prevails, as the stories of great scientists such as Darwin, Heisenberg and Marshall show.

\section{Howard Wolinsky \\ doi:10.1038/embor.2008.65}

